ORIGINAL RESEARCH

\title{
Depressed Mood, Perceived Health Competence and Health Behaviors: aCross-Sectional Mediation Study in Outpatients with Coronary Heart Disease
}

\author{
Vivian M. Yeh, $P h D^{1,2}$, Lindsay S. Mayberry, PhD, MS 1,2,3,4, Justin M. Bachmann, MD, MPH ${ }^{5}$, \\ Kenneth A. Wallston, $P h D^{1,6}$, Christianne Roumie, MD, MPH ${ }^{2,3,7}$, Daniel Muñoz, MD, MPA ${ }^{5}$, and \\ Sunil Kripalani, MD, MSC ${ }^{1,2,3}$ \\ ${ }^{1}$ Center for Health Services Research, Vanderbilt University Medical Center, Nashville, TN, USA; ${ }^{2}$ Center for Clinical Quality and Implementation \\ Research, Vanderbilt University Medical Center, Nashville, TN, USA; ${ }^{3}$ Department of Medicine, Vanderbilt University Medical Center, Nashville, TN, \\ USA; ${ }^{4}$ Center for Health Behavior and Health Education, Vanderbilt University Medical Center, Nashville, TN, USA; ${ }^{5}$ Division of Cardiovascular \\ Medicine, Vanderbilt University Medical Center, Nashville, TN, USA; ${ }^{6}$ School of Nursing, Vanderbilt University, Nashville, TN, USA; ${ }^{7}$ Veterans Health \\ Administration-Tennessee Valley Healthcare System Geriatric Research Education Clinical Center (GRECC), Nashville, TN, USA.
}

BACKGROUND: Identifying potential mechanisms that link depressed mood with worse health behaviors is important given the prevalence of depressed mood in patients with coronary heart disease (CHD) and its relationship with subsequent mortality. Perceived health competence is an individual's confidence in his/her ability to successfully engineer solutions to achieve health goals and may explain how depressed mood affects multiple health behaviors.

OBJECTIVE: Examine whether or not perceived health competence mediates the relationship between depressed mood and worse health behaviors.

DESIGN: A cross-sectional study conducted by the Patient-Centered Outcomes Research Institute-funded Mid-South Clinical Data Research Network between August 2014 and September 2015. Bootstrapped mediation was used.

PARTICIPANTS: Patients with coronary heart disease $(n=2334)$.

MAIN MEASURES: Two items assessing perceived health competence, a single item assessing depressed mood, and a Health Behaviors Index including: the International Physical Activity Questionnaire (IPAQ); select items from the National Adult Tobacco Survey and the Alcohol Use Disorder Inventory Test; and single items assessing diet and medication adherence.

KEY RESULTS: Depressed mood was associated with lower perceived health competence $(a=-0.21, p<.001)$ and lower perceived health competence was associated with worse performance on a Health Behaviors Index $(b=$ $0.18, p<.001)$. Perceived health competence mediated the influence of depressed mood on health behaviors $(a b=-$ $0.04,95 \% \mathrm{CI}=-0.05$ to -0.03 ). The ratio of the indirect effect to the total effect was used as a measure of effect size $\left(\mathrm{P}_{\mathrm{M}}=0.26,95 \% \mathrm{CI}: 0.18\right.$ to 0.39$)$.

CONCLUSIONS: Depressed mood is associated with worse health behaviors directly and indirectly via lower perceived health competence. Interventions to increase perceived health competence may lessen the deleterious

Received February 6, 2018

Revised July 3, 2018

Accepted November 21, 2018

Published online December 18, 2018 impact of depressed mood on health behaviors and cardiovascular outcomes.

KEY WORDS: depressed mood; perceived health competence; health behavior; cardiovascular disease.

J Gen Intern Med 34(7):1123-30

DOI: $10.1007 / \mathrm{s} 11606-018-4767-1$

(C) Society of General Internal Medicine 2018

A pproximately $15 \%$ of individuals with coronary heart A disease (CHD) meet criteria for clinical depression ${ }^{1,2}$ and depressive symptomology is more than twice as common than clinical depression. ${ }^{1,3}$ Depression and CHD health outcomes have a grade-dependent relationship, and even subclinical depressive symptoms have been linked to increased healthcare utilization and mortality. ${ }^{4,5}$ Some evidence suggests this relationship is partially explained by biological (e.g., inflammation, platelet activation, hypothalamic-pituitaryadrenal (HPA) axis dysregulation) and behavioral pathways (e.g., health behaviors). The majority of CHD patients do not follow the recommended health behaviors necessary to benefit cardiac health $^{6,7}$ and adherence is even lower among those with depressive symptomology. 8,9

Understanding how depressed mood exerts an influence on multiple health behaviors, and how to efficiently assess this in the outpatient setting is important for clinic-based screening and interventions to improve health behaviors and outcomes. 5,10 One possible mechanism that links depressed mood to health outcomes is perceived health competence, which can be assessed by a two-item measure. Perceived health competence is an individual's confidence in his/her ability to successfully engineer solutions to achieve general health goals. ${ }^{11}$ It is a broader concept than self-efficacy, which pertains to an individual's belief in his/her ability to execute specific behaviors in specific situations (and therefore generally requires multiple 
questions to assess multiple behaviors). ${ }^{12}$ Experiencing depressed mood may dampen self-perceptions of one's ability to manage one's own health, ${ }^{13,}{ }^{14}$ lowering perceived health competence, and thereby adversely affecting multiple health behaviors. $^{15-17}$

The goal of this study is to examine perceived health competence as an explanatory construct for the impact of depressed mood on a Health Behaviors Index representing multiple behaviors known to influence cardiac health (i.e., healthy diet, physical activity, medication adherence, smoking, and alcohol consumption) in CHD outpatients. This line of inquiry could potentially identify a new intervention target for improving a broad range of health behaviors.

\section{METHOD}

\section{Design}

This was an observational cross-sectional secondary analysis from the Mid-South Coronary Heart Disease Cohort Study, which was developed under the Patient-Centered Outcomes Research Institute (PCORI) funded Mid-South Clinical Data Research Network (CDRN). This study includes data from Vanderbilt University Medical Center (VUMC), a tertiary care academic medical center, and clinical sites from the Vanderbilt Health Affiliated Network (VHAN), a clinically integrated network with more than 40 hospitals and 300 ambulatory care practices selected for their proximity to VUMC. This study was approved by the Vanderbilt University Institutional Review Board and recruitment procedures are published elsewhere. ${ }^{18}$

Procedures facilitated data collection in a large sample of outpatients by minimizing burden on participants and clinics. Study enrollment occurred between August 2014 and September 2015. Eligibility was determined in a review of electronic health records. Eligible patients who were scheduled for upcoming cardiology or primary care visit at VUMC or nearby VHAN sites were recruited in person by research staff. Additional approaches (e.g., email, mail, and telephone) were used to accommodate patients who missed their appointment, did not have an upcoming visit, or received care at other VHAN sites. All participants provided informed consent and were compensated \$10 to complete a 15-30-minute survey. Based on patient preference, surveys were completed via hard copy questionnaires, a secure web-based survey tool $\left(\right.$ REDCap $\left.^{19}\right)$, or telephone.

\section{Participants}

Eligibility was determined via a computable CHD phenotype. Briefly, individuals were considered to have CHD if they had (1) two outpatient visits on separate days with billing codes for prior myocardial infarction or obstructive coronary artery disease, or (2) one inpatient or outpatient procedure code for coronary artery bypass or percutaneous transluminal coronary angioplasty.
Individuals were excluded from the study if they were currently receiving hospice or were under 30 years of age (to exclude congenital non-atherosclerotic coronary disease). Additional exclusion criteria included impaired cognition (dementia, schizophrenia, or bipolar disorder documented in the medical chart), significant hearing loss, non-English speaking, or when the patient's illness severity prevented them from completing the survey after initial contact was made. If patients had difficulty reading, research assistants read the questions aloud.

Analyses indicated the demographic composition and clinical health of the recruited sample was similar to the larger Mid-South CDRN patient population. ${ }^{18}$

\section{Main Measures}

The majority of questionnaire items were selected from the PCORI common data model ${ }^{20}$ and the recommendations of the PCORI Patient-Reported Outcomes Task Force. All items were reviewed for clarity, content, and face validity by laypeople in a community engagement studio. ${ }^{21}$

Depressed Mood is one of two cardinal symptoms of clinical depression. ${ }^{22}$ Patients self-reported how frequently they "felt depressed" in the past 7 days, an item from the Patient Reported Outcomes Measurement Information System (PROMIS), a project which aims to create unidimensional item banks and derive short, psychometrically valid measures. ${ }^{23}$ Responses were recorded on a 5-point scale from "never" to "always" with higher scores indicating greater severity. Studies have confirmed construct validity of the PROMIS Depression Short-Form in various medical populations. $^{24,}{ }^{25}$ Additionally, the single-item of depressed mood was the most efficient indicator of depressive symptoms, ${ }^{26}$ correlating 0.827 and accounting for $68 \%$ of the total variance in a larger item bank.

Perceived Health Competence was assessed through the two-item Perceived Health Competence Scale (PHCS-2), a shortened version of the original eight-item $\mathrm{PHCS}^{27}$ The PHCS-2 has strong convergent validity with the full PHCS and is associated with health behaviors and quality of life. ${ }^{15,28}$ Patients were asked to indicate how much they agreed with the following statements: "I am able to do things for my health as well as most other people" and "It is difficult for me to find effective solutions for my health problems." Response options were on a five-point scale ranging from "strongly disagree" to "strongly agree." The second question was reversed coded; then the items were summed, with higher scores indicating greater perceived health competence.

Health behaviors were measured using an index constructed from five domains (diet, physical activity, medication adherence, smoking, and alcohol use), modeling procedures outlined in previous work. ${ }^{15}$ Domain scores were rescaled to fit a range of scores from 1 (the least healthy behaviors) to 5 (the most healthy behaviors). The final index score was the sum of the five domain scores and ranged from 5 to 25 . Index scores were only computed when all five domains were present. 
Healthy diet was assessed with the single-item Healthy Eating Index-2010 from the National Health and Nutrition Examination Survey. ${ }^{29}$ Individuals were asked: "In general, how healthy is your overall diet?" Responses were made on a five-point scale from "poor" (1) to "excellent" (5). The Healthy Eating Index-2010 is a reliable and valid measure that distinguishes the healthfulness of $\operatorname{diets}^{30}$ and yields comparable results to longer assessments of 24-hour dietary recall. ${ }^{31}$

Physical activity was assessed through the short version of the International Physical Activity Questionnaire (IPAQ), a valid and reliable ${ }^{32}$ seven-item survey that assesses an individual's activity across multiple physical activity domains. ${ }^{33}$ Total metabolic (MET) minutes per week were calculated in accordance with established guidelines. ${ }^{33}$ Similar to previous research, ${ }^{34}$ individuals were assigned categorical scores for activity levels: 1 for low activity (e.g., <600 METs), 3 for moderate activity (e.g., $\geq 600$ METs and<3000 METs), and 5 for high activity (e.g., $3000 \mathrm{METs}+$ ).

Medication adherence was assessed through a question asking patients "how many days in the past week did you miss taking one or more of your prescription medicines?" This valid single item has predicted hospitalization and mortality in past CHD populations ${ }^{35}$ and is included in the PCORI Core and Recommended Patient-Reported Outcomes Common Measures as well as other measure sets. ${ }^{36}$ Patients responded with the number of days ( 0 to 7$)$ they missed medications or that they were not currently taking any prescription medications. The number of days missed was reverse scored and rescaled to create a continuous value ranging from 1 to 5 , where 5 indicates better adherence.
Smoking was assessed with a series of questions from the National Adult Tobacco Survey (CDC 2009-2010). ${ }^{37}$ Recent epidemiological work indicates current smoking intensity is a stronger predictor of cardiovascular disease outcomes than packyears. ${ }^{38}$ We therefore operationalized smoking behavior by the current number of cigarettes smoked per day. Never or past smokers smoked zero cigarettes per day. Next, cigarettes per day were rescaled and reversed, such that the heaviest smokers were assigned a 1 and never or past smokers were assigned a 5 .

Alcohol use was measured with two questions from the Alcohol Use Disorder Inventory Test. ${ }^{39}$ Following earlier work in cardiovascular populations, ${ }^{15}$ heavier use was coded as 1 , no use was coded as 3, and light-moderate use was coded as 5. In prior dose-response epidemiological studies, individuals with light to moderate alcohol consumption are at the lowest risk for negative cardiovascular outcomes. ${ }^{40,41}$

Covariates included sociodemographic items - age, difficulty paying monthly bills, gender, marital status, race and ethnicity. Relationship status was coded as living with a spouse/partner versus not. Minority status was calculated from race and ethnicity with non-Whites and Hispanics considered as minorities.

\section{Data Analysis}

Variations in patient characteristics, perceived health competence and health behaviors by depressed mood levels were summarized. Next, a mediation model was constructed to evaluate the relationships among depressed mood, perceived health competence, and the Health Behaviors Index. All estimated paths were adjusted with covariates. The covariates

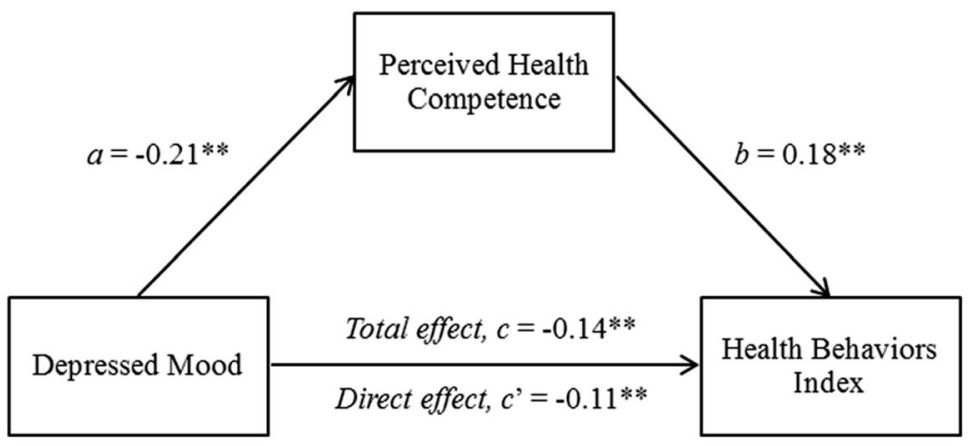

Indirect effect, $a b=-0.04,95 \% \mathrm{CI}:-0.05$ to -0.03

$* * p<.001$

*All paths are presented in standardized regression coefficients. The indirect path $a b$ is a product of the $a$ path and $b$ path. The direct effect of depressed mood on the Health Behaviors Index with perceived health competence in the model is represented by the $c^{\prime}$ path.

Fig. 1 Adjusted mediation results of depressed mood on health behaviors through perceived health competence. Adjusted mediation results of depressed mood on health behaviors through perceived health competence. ${ }^{¥}$ All paths are presented in standardized regression coefficients. The indirect path $a b$ is a product of the $a$ path and $b$ path. The direct effect of depressed mood on the Health Behaviors Index with perceived health competence in the model is represented by the $c$ ' path 
were prespecified based on previously documented associations with depressed mood, perceived health competence, and health behaviors. Models were adjusted to include sex, minority status, age, relationship status, and financial strain (i.e., difficulty paying monthly bills). We used listwise deletion to handle missing data; only participants with complete data were retained in analyses.

The mediation model was conducted using a bootstrapping approach to path analysis with the PROCESS syntax ${ }^{42}$ in IBM SPSS Statistics $24 .{ }^{43}$ Ordinary least squares regression was used to estimate the relationship of each path in the mediation model (Fig. 1). Path $a$ estimates the relationship between depressed mood and perceived health competence while path $b$ estimates the relationship between perceived health competence and the Health Behaviors Index while adjusted for depressed mood. Path $c$ estimates the relationship between depressed mood and the Health Behaviors Index without the mediator in the model (the total effect). Path $c$ ' estimates the relationship between depressed mood and the Health Behaviors Index with perceived health competence in the model (the direct effect). Lastly, the mediation effect is represented by path $a b$ (the indirect effect), which represents the indirect influence of depressed mood on the Health Behaviors Index through perceived health competence.

All path estimations were bias-corrected using 10,000 bootstrap samples with replacement, and $95 \%$ confidence intervals were obtained from the upper and lower limits of the sampling distribution. In contrast to the causal steps approach of mediation, which indirectly infers significance of a mediator based on the significance of paths between the predictor, mediator and outcome variables, ${ }^{44}$ bootstrapping directly tests the product of $a$ and $b$ paths, and whether or not zero falls within the confidence interval around the parameter of the indirect effect. ${ }^{45}$ This bootstrapping approach results in more accurate estimates of confidence intervals because it is less susceptible to sample size ${ }^{45}$ and makes no assumption of the normality of the $a b$ path. ${ }^{42,} 46$

State of the art mediation methods do not compare the size of the total (path $c$ ) and direct paths (path $c^{\prime}$ ) to determine the degree of mediation. ${ }^{45,}{ }^{47}$ Rather, the ratio of the indirect to the total effect $\left(P_{M}\right)$ provides information on the relative size of the mediation effect. ${ }^{47}$ The characteristics of this dataset permit the usage of $P_{M}$ given the sample size $(N>500)$, the consistent direction of the indirect and total effects, and because the total effect was greater than the indirect effect. ${ }^{47,48}$

\section{RESULTS}

\section{Sample}

The final sample included 2334 patients with CHD (Table 1). Depressed mood was reported by $0.9 \%$ of the sample as occurring "always," $4.5 \%$ as "often," $21.9 \%$ as "sometimes," $27.3 \%$ as "rarely," and $45.4 \%$ as "never." Perceived health competence had a median score of 8 (out of 10) and an
Table 1 Patient characteristics of the Mid-South Coronary Heart Disease Study

\begin{tabular}{|c|c|}
\hline Variable & $n=2334$ \\
\hline \multicolumn{2}{|l|}{ Demographics } \\
\hline Age, median(IQR) & $68.9(61.3-75.7)$ \\
\hline \multicolumn{2}{|l|}{$\operatorname{Sex}, N(\%)$} \\
\hline Male & $1594(68.3 \%)$ \\
\hline \multicolumn{2}{|l|}{ Minority status, $N(\%)$} \\
\hline White & $2126(91.1 \%)$ \\
\hline Non-White & $208(8.9 \%)$ \\
\hline \multicolumn{2}{|l|}{ Relationship status, $N(\%)$} \\
\hline Living with partner or spouse & $1660(71.1 \%)$ \\
\hline \multicolumn{2}{|l|}{ Education, $N(\%)$} \\
\hline 8th grade or less & $94(4.0 \%)$ \\
\hline Some high school & $128(5.5 \%)$ \\
\hline High school graduate or GED & $574(24.6 \%)$ \\
\hline Some college or 2-year degree & $670(28.7 \%)$ \\
\hline College graduate & $382(16.4 \%)$ \\
\hline More than college & $486(20.8 \%)$ \\
\hline \multicolumn{2}{|l|}{ Psychosocial and physical factors } \\
\hline Difficulties paying bills, median $(\mathrm{IQR})^{\mathrm{a}}$ & $2(1-3)$ \\
\hline \multicolumn{2}{|l|}{ Depressed mood, $N(\%)^{b}$} \\
\hline Never & $1060(45.4 \%)$ \\
\hline Rarely & $637(27.3 \%)$ \\
\hline Sometimes & $510(21.9 \%)$ \\
\hline Often & $105(4.5 \%)$ \\
\hline Always & $22(0.9 \%)$ \\
\hline Perceived Health Competence Scale & $8(6-10)$ \\
\hline \multicolumn{2}{|l|}{ (PHCS-2), ${ }^{\mathrm{C}}$ median (IQR) } \\
\hline \multicolumn{2}{|l|}{ Health behaviors } \\
\hline Overall Health Behaviors Index ${ }^{\mathrm{d}}$ & $18.98(2.42)$ \\
\hline Diet Subindex, $\mathrm{M}(\mathrm{SD})^{\mathrm{e}}$ & $3.13(0.95)$ \\
\hline \multicolumn{2}{|l|}{ Physical Activity Subindex } \\
\hline Low (<600 weekly METs) & 1094(46.9\%) \\
\hline Moderate ( $>600$ and $<3000$ weekly METs) & $891(38.2 \%)$ \\
\hline High $(>30 \overline{0} 0$ weekly METs $)$ & $349(15.0 \%)$ \\
\hline Medication Adherence Subindex, $\mathrm{M}(\mathrm{SD})^{\mathrm{f}}$ & $4.75(0.56)$ \\
\hline Smoking Subindex, M(SD) & $4.92(0.34)$ \\
\hline \multicolumn{2}{|l|}{ Alcohol Subindex, $N(\%)$} \\
\hline Heavier use & $112(4.8 \%)$ \\
\hline No use & $1155(49.5 \%)$ \\
\hline Light-moderate use & $1067(45.7 \%)$ \\
\hline
\end{tabular}

Missing counts in the excluded sample for age $=1 ;$ Sex $=0 ;$ Minority Status $=66 ;$ Relationship Status $=10 ;$ Education $=37 ;$ Difficulty Paying Bills = 28; Depressed Mood = 12; Perceived Health Competence = 14; Health Behaviors Index=142; Diet Subindex =13; Physical Activity Subindex =15; Medication Adherence Subindex = 27; Smoking Subindex $=46 ;$ Alcohol Subindex $=50$

MET metabolic equivalent

${ }^{a}$ Score was from 1 to 4 , with higher scores indicating greater difficulty ${ }^{b}$ Score was from 1 "never" to 5 "always," with higher scores indicating greater severity

${ }^{c}$ PHCS-2 is a score from 1 to 10 , with higher scores indicated greater perceived competence

${ }^{d}$ Continuous score from 1 to 25 , with higher scores indicating better health behaviors

${ }^{e}$ Continuous score from 1 to 5 , with higher scores indicating healthier diet

${ }^{f}$ Continuous score was from 1 to 5 , with higher scores indicating greater adherence

interquartile range of 6 to 10 . The degree to which participants engaged in each of the five health behaviors that comprise the index are shown in Table 1. An index score was only computed when all five subindices were present. A total of 271 patients were excluded from subsequent analyses due to missing data. Excluded patients and those retained in the sample of $n=2334$ for mediation analyses had similar characteristics.

Descriptive statistics summarizing how perceived health competence and health behaviors varied by each level of 
depressed mood are presented in Table 2. Overall, healthier behaviors and higher perceived health competence were more common among participants reporting the least depressed mood except for medication adherence, which was similar regardless of the degree of depressed mood reported. Additionally, while heavier alcohol use was present at similar levels regardless of depressed mood, light to moderate use was more prevalent when depressed mood was lower.

\section{Mediation}

Figure 1 visually represents the mediation results. The standardized regression coefficients of each path and covariate in the mediation model are reported in Table 2. Depressed mood was associated with lower perceived health competence ( $a=$ $-0.21, p<0.001)$ and predicted worse health behaviors in the model unadjusted for perceived health competence (total effect, $c=-0.14, p<0.001)$. Lower perceived health competence was associated with worse health behaviors $(b=0.18$, $p<0.001)$ after adjustment for depressed mood. The indirect effect was significant ( $a b=-0.04,95 \% \mathrm{CI}:-0.05$ to -0.03 ), indicating mediation. The ratio of the indirect to the total effect $\left(P_{M}=0.26,95 \%\right.$ CI: 0.18 to 0.39 ) shows that the indirect effect $(a b)$ was approximately a quarter as large as the total effect of depressed mood on health behaviors $(c)$.

In the fully adjusted mediation model, a few covariates remained significant predictors of worse health behaviors: patients who did not live with a spouse or partner and had more financial strain reported worse health behaviors (all $p<0.001)$. In contrast, individuals with higher education levels were more likely to engage in health behaviors $(p<0.001)$. Minority status, age, and gender did not independently predict health behaviors.

\section{DISCUSSION}

In this study of outpatients with CHD, depressed mood influenced performance on a Health Behaviors Index directly and indirectly through perceived health competence (Table 3 ).
These findings suggest that the lower perceived health competence experienced by outpatients with depressed mood may be one mechanism linking depressed mood to worse health behaviors among patients with $\mathrm{CHD},{ }^{8,9}$ accounting for approximately a quarter of the total effect of depressed mood on health behaviors.

The two-item Perceived Health Competence Scale may be a useful risk marker of poor health behaviors and an intervention target to improve multiple health behaviors in outpatients with depressed mood. While depressed mood continued to exert a direct impact on health behaviors with perceived health competence in the model, a finding consistent with previous work, ${ }^{15}$ targeting depressed mood alone might not be effective. Depression interventions have inconsistent effects on CHD health outcomes ${ }^{49}$ perhaps because they generally focus on improving $\operatorname{mood}^{50}$ and changing mood alone is insufficient to spark behavior change. ${ }^{51-53}$ Self-efficacy interventions that target specific behaviors may increase physical activity levels, ${ }^{54}$ vegetable and fruit intake, ${ }^{55}$ and medication adherence. ${ }^{56}$ Future studies of health coaching interventions that build perceived health competence $^{57}$ are needed to establish if perceived health competence can exert positive effects across multiple health behaviors.

While depressed mood significantly impacted health behaviors both directly and indirectly, the overall mediation model explained about a fifth of the total variance in health behaviors. Similarly, depressed mood had a limited effect on health behaviors without perceived health competence in the model. For every one standard deviation increase in depressed mood, the Health Behaviors Index decreased by approximately one sixth standard deviation. These smaller sizes may be due to the breadth of the Health Behaviors Index. For example, age and gender were not related to health behaviors assessed in the index. Perhaps older adults have lower physical activity and women have healthier diets, but neither of the demographic variables consistently exerted an influence on the other health behaviors in the index. Using the index was necessary; however, to study whether or not perceived health competence, a broad construct hypothesized to influence multiple health behaviors, performed as expected.

Table 2 Perceived health competence and health behaviors by level of depressed mood

\begin{tabular}{|c|c|c|c|c|c|}
\hline \multirow[t]{2}{*}{ Health behaviors $^{\mathrm{a}}$} & \multicolumn{5}{|c|}{ In the past 7 days, I felt depressed: } \\
\hline & Never & Rarely & Sometimes & Often & Always \\
\hline Perceived health competence, $\mathrm{M}(\mathrm{SD})$ & $8.4(1.8)$ & $7.9(1.8)$ & $7.3(2.0)$ & $6.4(1.9)$ & $6.2(2.5)$ \\
\hline Overall Health Behavior Index, M(SD) & $19.4(2.4)$ & $19.0(2.3)$ & $18.3(2.3)$ & $17.6(2.2)$ & $16.9(2.1)$ \\
\hline Diet Subindex, M(SD) & $3.4(0.9)$ & $3.1(0.9)$ & $2.8(0.9)$ & $2.5(1.0)$ & $2.6(1.0)$ \\
\hline \multicolumn{6}{|l|}{ Physical ActivitySubindex, $N(\%)$} \\
\hline Low (<600 weekly METs) & $487(41.7 \%)$ & $316(45.0 \%)$ & $321(56.7 \%)$ & $75(62.5 \%)$ & $19(82.6 \%)$ \\
\hline Moderate (> 600 and $<3000$ weekly METs) & $490(41.9 \%)$ & $280(39.8 \%)$ & $179(31.6 \%)$ & $33(27.5 \%)$ & $4(17.4 \%)$ \\
\hline High (> 3000 weekly METs) & $192(16.4 \%)$ & $107(15.2 \%)$ & $66(11.7 \%)$ & $12(10.0 \%)$ & $0(0.0 \%)$ \\
\hline Medication Adherence Subindex, M(SD) & $4.8(0.5)$ & $4.7(0.6)$ & $4.8(0.5)$ & $4.7(0.6)$ & $4.8(0.5)$ \\
\hline Smoking Subindex, M(SD) & $4.9(0.3)$ & $4.9(0.3)$ & $4.9(0.4)$ & $4.8(0.5)$ & $4.6(0.9)$ \\
\hline \multicolumn{6}{|l|}{ Alcohol Subindex, $N(\%)$} \\
\hline Heavier use & $60(5.2 \%)$ & $29(4.2 \%)$ & $23(4.1 \%)$ & $5(4.3 \%)$ & $1(4.3 \%)$ \\
\hline No use & $544(47.3 \%)$ & $338(48.5 \%)$ & $311(55.8 \%)$ & $70(60.3 \%)$ & $14(60.9 \%)$ \\
\hline Light-moderate use & $547(47.5 \%)$ & $330(47.3 \%)$ & $223(40.0 \%)$ & $41(35.3 \%)$ & $8(34.8 \%)$ \\
\hline
\end{tabular}

${ }^{a}$ Higher scores indicate healthier behaviors on continuous behavior scores 
Table 3 Adjusted mediation results of depressed mood on health behaviors through perceived health competence

\begin{tabular}{|c|c|c|c|c|c|c|c|c|}
\hline \multicolumn{9}{|l|}{$\overline{\text { Consequent }}$} \\
\hline & & \multicolumn{4}{|c|}{ Perceived health competence } & \multicolumn{3}{|c|}{ HealthBehaviors Index } \\
\hline \multirow{2}{*}{$\begin{array}{l}\text { Total effect of Depressed Mood } \\
\text { on the Health Behaviors Index }\end{array}$} & path $c$ & \multicolumn{7}{|c|}{$-0.14, p \leq 0.001$} \\
\hline & & Coeff. & $S E$ & $P$ & & Coeff. & $S E$ & $P$ \\
\hline Depressed mood & path $a$ & -0.21 & 0.02 & $<0.001$ & path c' & -0.11 & 0.02 & $<0.001$ \\
\hline Perceived health competence & & - & - & - & path $b$ & 0.18 & 0.02 & $<0.001$ \\
\hline Constant & $i_{1}$ & 0.03 & 0.10 & 0.76 & $i_{2}$ & 0.31 & 0.10 & 0.001 \\
\hline \multicolumn{9}{|l|}{ Covariates } \\
\hline Sex (female) & & 0.03 & 0.04 & 0.51 & & -0.06 & 0.04 & 0.18 \\
\hline Education & & 0.18 & 0.02 & $<0.001$ & & 0.19 & 0.02 & $<0.001$ \\
\hline Minority & & -0.06 & 0.07 & 0.37 & & -0.01 & 0.07 & 0.91 \\
\hline Age & & -0.01 & 0.02 & 0.58 & & 0.02 & 0.02 & 0.34 \\
\hline Living with partner or spouse & & 0.01 & 0.05 & 0.87 & & -0.18 & 0.05 & $<0.001$ \\
\hline Financial strain & & $\begin{array}{l}-0.16 \\
R^{2}=.15\end{array}$ & 0.02 & $<0.001$ & & $\begin{array}{l}-0.08 \\
R^{2}=.17\end{array}$ & 0.02 & $<0.001$ \\
\hline $\begin{array}{l}\text { Indirect effect of Depressed Mood } \\
\text { on the Health Behaviors Index }\end{array}$ & path $a b$ & \multicolumn{4}{|c|}{$\begin{array}{l}F(7,2326)=56.90, p \leq<0.001 \\
-0.04(95 \% \mathrm{CI}=-0.05 \text { to }-0.03)\end{array}$} & \multicolumn{3}{|c|}{$F(8,2325)=57.93, p \leq<0.001$} \\
\hline
\end{tabular}

All paths are presented in standardized regression coefficients (see Fig. 1 for alternate depiction of mediation analyses)

This study had several limitations. First, longitudinal mediation studies that manipulate the predictor and mediator are necessary to examine causality. ${ }^{58}$ In our cross-sectional design, it remains possible that an unmeasured construct, such as pessimism or social desirability bias, may be affecting depressed mood, perceived health competence, and health behaviors in a manner consistent with our findings. Additionally, greater perceived health competence may decrease depressed mood and improve health behaviors. Second, although study demographics reflect the patients within the Mid-South CDRN, results may not generalize to minority populations given low representation in this sample. Third, our assessment of depressed mood did not include anhedonia, a marker of depression which some studies suggest may be particularly cardiotoxic. ${ }^{59}$ Fourth, we categorized lightmoderate alcohol use as the healthiest level of alcohol consumption in the health behavior index because of prior observational evidence indicating patients with lightmoderate use have the least cardiovascular risk; ${ }^{40,}{ }^{41}$ however, the relationship between alcohol use and outcomes for CHD patients remains complex and it is possible that healthier patients choose light-moderate drinking instead of lightmoderate drinking positively influencing health. In the absence of randomized trials, we made this decision but alternative decisions about the classification of healthy levels of alcohol consumption could be supported. Lastly, single item measures were used to assess diet, medication adherence, and depressed mood while longer measures possibly would have greater reliability and/or validity; ${ }^{60}$ however, these single-item measures were found to have validity in prior research and community engagement studios ${ }^{21}$ and facilitate pragmatic studies in clinical settings with low participant and provider burden, a primary study design goal under the Clinical Data Research Networks.
Overall, our findings suggest lowered perceived health competence may be one of the reasons why depressed mood has a negative impact on the multiple health behaviors known to impact cardiovascular health. Perceived health competence can be quickly assessed in outpatient settings and may provide insight into a patient's likelihood of engaging in a variety of health behaviors. Since depressed mood also directly impacts health behaviors, interventions targeting both depressed mood and perceived health competence may be necessary to improve a wide range of recommended health behaviors.

Corresponding Author: Vivian M. Yeh, PhD; Center for Health Services Research Vanderbilt University Medical Center, Nashville, TN, USA (e-mail: vivian.m.yeh@vumc.org).

Contributors There are no additional contributors to this manuscript.

Funders Research reported in this publication was supported by grants from the Patient-Centered Outcomes Research Institute (PCORI, $R$-1306-04869 and 1501-26498) and in part by the National Center for Advancing Translational Sciences of the National Institute of Health under Award Number UL1 TROOO445 and grant number K12HS022990 from the Agency for Healthcare Research and Buality (Bachmann).The content is solely the responsibility of the authors and does not necessarily represent the official views of the funding agencies.

Prior Presentations None.

Data Availability The datasets during and/or analyzed during the current study are available from the corresponding author on reasonable request.

\section{Compliance with Ethical Standards:}

Conflicts of Interest: Kenneth A. Wallston is a member of the Advisory Board of EdLogics, Inc.

Sunil Kripalani has consultancies with SAI Interactive and Verustat, as well as stock ownership in Bioscape Digital.

All other authors declare no conflicts of interest. 
Publisher's note Springer Nature remains neutral with regard to jurisdictional claims in published maps and institutional affiliations.

\section{REFERENCES}

1. Tully PJ, Baker RA. Depression, anxiety, and cardiac morbidity outcomes after coronary artery bypass surgery: a contemporary and practical review. J Geriatr Cardiol. 2012;9(2):197-208. https://doi.org/ 10.3724/sp.j.1263.2011.12221

2. Thombs BD, de Jonge $\mathbf{P}$, Coyne JC, et al. Depression screening and patient outcomes in cardiovascular care: a systematic review. JAMA. 2008;300(18):2161-71. https://doi.org/10.1001/jama.2008.667

3. Cay EL, Vetter N, Philip AE, Dugard P. Psychological status during recovery from an acute heart attack. J Psychosom Res. 1972;16(6):42535.

4. Hare DL, Toukhsati SR, Johansson P, Jaarsma T. Depression and cardiovascular disease: a clinical review. Eur Heart J. 2013:35(21):136572.

5. Rozanski A, Blumenthal JA, Davidson KW, Saab PG, Kubzansky L. The epidemiology, pathophysiology, and management of psychosocial risk factors in cardiac practice: The emerging field of behavioral cardiology. J Am Coll Cardiol. 2005;45(5):637-51. https://doi.org/10.1016/j.jacc 2004.12.005

6. Huffman MD, Capewell S, Ning H, Shay CM, Ford ES, Lloyd-Jones DM. Cardiovascular Health Behavior and Health Factor Changes (19882008) and Projections to 2020Clinical Perspective. Circulation. 2012;125(21):2595-602.

7. Lloyd-Jones DM, Hong Y, Labarthe D, Mozaffarian D, Appel LJ, VanHorn L, et al. Defining and setting national goals for cardiovascular health promotion and disease reduction. Circulation. 2010;121(4):586613.

8. Ziegelstein RC, Fauerbach JA, Stevens SS, Romanelli J, Richter DP, Bush DE. Patients with depression are less likely to follow recommendations to reduce cardiac risk during recovery from a myocardial infarction. Arch Intern Med. 2000;160(12):1818-23.

9. Gehi A, Haas D, Pipkin S, Whooley MA. Depression and medication adherence in outpatients with coronary heart disease: findings from the Heart and Soul Study. Arch Intern Med. 2005; 165(21):2508-13. https:// doi.org/10.1001/archinte.165.21.2508

10. Maruthur NM, Wang N-Y, Appel LJ. Lifestyle interventions reduce coronary heart disease risk. Circulation. 2009; 119(15):2026-31.

11. Smith MS, Wallston KA, Smith CA.The development and validation of the Perceived Health Competence Scale. Health Educ Res. 1995; 10(1):5164.

12. Bandura A. Guide for constructing self-efficacy scales. In: Pajares F, Urdan T, eds. Self-efficacy beliefs of adolescents. Charlotte: Information Age Publishing; 2006:307-37.

13. Kavanagh DJ, Bower GH. Mood and self-efficacy: Impact of joy and sadness on perceived capabilities. Cognit Ther Res. 1985;9(5):507-25.

14. Konttinen H, Silventoinen $\mathbf{K}$, Sarlio-Lähteenkorva S, Männistö S, Haukkala A. Emotional eating and physical activity self-efficacy as pathways in the association between depressive symptoms and adiposity indicators. Am J Clin Nutr. 2010;92(5): 1031-9.

15. Bachmann JM, Goggins KM, Nwosu SK, Schildcrout JS, Kripalani S, Wallston KA. Perceived health competence predicts health behavior and health-related quality of life in patients with cardiovascular disease. Patient Educ Couns. 2016;99(12):2071-9. https://doi.org/10.1016/j. pec.2016.07.020

16. Bachmann JM, Wallston KA, Roumie CL, Munoz D, Patel N, Kripalani S eds. Health Self-efficacy is Associated With Increased Physical Activity in Patients With Coronary Heart Disease. American Heart Association Scientific Sessions; Orlando: Am Heart Assoc; 2015.

17. Christensen AJ, Wiebe JS, Benotsch EG, Lawton WJ. Perceived health competence, health locus of control, and patient adherence in renal dialysis. Cognit Ther Res. 1996;20(4):411-21.

18. Heerman WJN, Roumie C, Harris P, Rosenbloom ST, Pulley J, Wilkins C, Williams N, Crenshaw C, Leak C, Scherdin J, Munoz D, Bachmann J, Rothman J, Kripalani S. Recruitment Methods for Survey Research: Findings from the Mid-South Clinical Data Research. Contemp Clin Trials. 2017;62:50-5. https://doi.org/10.1016/j.cct.2017.08.006

19. Harris PA, Taylor R, Thielke R, Payne J, Gonzalez N, Conde JG Research electronic data capture (REDCap)—a metadata-driven method ology and workflow process for providing translational research informat ics support. J Biomed Inform. 2009;42(2):377-81. https://doi.org/10. 1016/j.jbi.2008.08.010
20. PCORnet Common Data Model (CDM). 2017. Available from: https:// pcornet.org/pcornet-common-data-model/. Accessed 12 April 2018.

21. Joosten YA, Israel TL, Williams NA, Boone LR, Schlundt DG, Mouton CP, et al. Community engagement studios: a structured approach to obtaining meaningful input from stakeholders to inform research. Acad Med. 2015;90(12):1646-50. https://doi.org/10.1097/ACM. 0000000000000794

22. Regier DA, Kuhl EA, Kupfer DJ. The DSM-5: Classification and criteria changes. World Psychiatry. 2013;12(2):92-8.

23. Cella D, Riley W, Stone A, Rothrock N, Reeve B, Yount S, et al. The Patient-Reported Outcomes Measurement Information System (PROMIS) developed and tested its first wave of adult self-reported health outcome item banks: 2005-2008. J Clin Epidemiol. 2010;63(11):1179-94.

24. Kroenke K, Yu Z, Wu J, Kean J, Monahan PO. Operating Characteristics of PROMIS Four-Item Depression and Anxiety Scales in Primary Care Patients with Chronic Pain. Pain Med. 2014;15(11):1892-901. https://doi.org/10.1111/pme.12537

25. Monique H, L. BJ, Krishna T, John V, Anh C, Sofia P, et al. Validity of two new patient-reported outcome measures in systemic sclerosis: Patient-reported outcomes measurement information system 29-item health profile and functional assessment of chronic illness therapydyspnea short form. Arthritis Care Res (Hoboken). 2011;63(11):1620-8. https://doi.org/10.1002/acr.20591

26. Choi SW, Reise SP, Pilkonis PA, Hays RD, Cella D. Efficiency of static and computer adaptive short forms compared to full-length measures of depressive symptoms. Qual Life Res. 2010;19(1):125-36. https://doi. org/10.1007/s11136-009-9560-5

27. Smith MS, Wallston KA, Smith CA.The development and validation of the Perceived Health Competence Scale. Health Educ Res. 1995;10(1):5164.

28. Dempster M, Donnelly M. Validity of the Perceived Health Competence Scale in a UK primary care setting. Psychol Health Med. 2008;13(1):1237. https://doi.org/10.1080/13548500701351984

29. Variyam JN, Lin B-H. NHANES: Development of a flexible consumer behavior survey module. The FASEB Journal. 2007;21(5):A53-A.

30. Guenther PM, Kirkpatrick SI, Reedy J, Krebs-Smith SM, Buckman DW, Dodd KW, et al. The Healthy Eating Index-2010 is a valid and reliable measure of diet quality according to the 2010 Dietary Guidelines for Americans. J Nutr. 2014;144:399-407. https://doi.org/10.3945/jn. 113.183079

31. Adjoian TK, Firestone MJ, Eisenhower D, Stella SY. Validation of selfrated overall diet quality by Healthy Eating Index-2010 score among New York City adults, 2013. Prev Med Rep. 2016;3:127-31. https://doi.org/ 10.1016/j.pmedr.2016.01.001

32. Hallal PC, Victora CG. Reliability and validity of the international physical activity questionnaire (IPAQ). Med Sci Sports Exerc. 2004;36(3):556.

33. The IPAQ Group. Guidelines for Data Processing and Analysis of the International Physical Activity Questionnaire (IPAQ) - Short and Long Forms. 2005. Available from: https://sites.google.com/site/theipaq/ home. Accessed October 92018.

34. Klompstra L, Jaarsma T, Stromberg A. Physical activity in patients with heart failure: barriers and motivations with special focus on sex differences. Patient Prefer Adherence. 2015;9:1603-10. https://doi.org/10. 2147/ppa.s90942

35. Wu JR, DeWalt DA, Baker DW, Schillinger D, Ruo B, Bibbins-Domingo $\mathbf{K}$, et al. A single-item self-report medication adherence question predicts hospitalisation and death in patients with heart failure. J Clin Nurs. 2014;23(17-18):2554-64. https://doi.org/10.1111/jocn.12471

36. Regenstrief Institute I. Logical Observation Identifiers Names and Codes (LOINC) Committee. 2017. Available from: https://r.details.loinc.org/ LOINC/68513-1.html?sections=Comprehensive. Accessed October 9 2018.

37. Centers for Disease Control and Prevention. 2009-2010 National Adult Tobacco Survey. Methodology Report. Unpublished Report; 2011.

38. Nance R, Delaney J, McEvoy JW, Blaha MJ, Burke GL, Navas-Acien A et al. Smoking intensity (pack/day) is a better measure than pack-years or smoking status for modeling cardiovascular disease outcomes. J Clin Epidemiol. 2017;81:111-9. https://doi.org/10.1016/j.jclinepi.2016.09. 010

39. Saunders JB, Aasland OG, Babor TF, De la Fuente JR, Grant M. Development of the alcohol use disorders identification test (AUDIT) WHO collaborative project on early detection of persons with harmful alcohol consumption-II. Addiction. 1993;88(6):791-804. 
40. Rimm EB, Klatsky A, Grobbee D, Stampfer MJ. Review of moderate alcohol consumption and reduced risk of coronary heart disease: is the effect due to beer, wine, or spirits? BMJ. 1996;312(7033):731-6.

41. Ronksley PE, Brien SE, Turner BJ, Mukamal KJ, Ghali WA. Association of alcohol consumption with selected cardiovascular disease outcomes: a systematic review and meta-analysis. BMJ. 2011;342. https:// doi.org/10.1136/bmj.d671

42. Hayes AF. Introduction to mediation, moderation, and conditional process analysis: a regression-based approach. New York City: Guilford Press; 2013.

43. IBM SPSS Statistics for Windows. Version 24.0. [software]. 2016 September 1 [cited 2018 February 9]. Available from: http://www-01.ibm.com/ support/docview.wss?uid=swg24041224

44. Baron RM, Kenny DA. The moderator-mediator variable distinction in social psychological research: Conceptual, strategic, and statistical considerations. J Pers Soc Psychol. 1986;51(6): 1173.

45. Hayes AF. Beyond Baron and Kenny: Statistical mediation analysis in the new millennium. Commun Monogr. 2009;76(4):408-20.

46. Preacher KJ, Hayes AF. Asymptotic and resampling strategies for assessing and comparing indirect effects in multiple mediator models. Behav Res Methods. 2008;40(3):879-91.

47. Wen Z, Fan X. Monotonicity of effect sizes: questioning kappa-squared as mediation effect size measure. Psychol Methods. 2015;20(2):193. https://doi.org/10.1037/met0000029

48. MackinnonDP, KrullJL, LockwoodCM. Equivalence of the mediation, confounding and suppression effect. Prev Sci. 2000; 1(4):173-81.

49. Richards SH, Anderson L, Jenkinson CE, Whalley B, Rees K, Davies P, et al. Psychological interventions for coronary heart disease. Cochrane Database Syst Rev. 2017;4:Cd002902. https://doi.org/10.1002/ 14651858.CD002902.pub4

50. Rutledge T, Reis VA, Linke SE, Greenberg BH, Mills PJ. Depression in heart failure: a meta-analytic review of prevalence, intervention effects, and associations with clinical outcomes. J Am Coll Cardiol. 2006;48(8): 1527-37.

51. Kronish IM, Rieckmann N, Burg MM, Edmondson D, Schwartz JE, Davidson KW. The effect of enhanced depression care on adherence to risk-reducing behaviors after acute coronary syndromes: findings from the COPES trial. Am Heart J. 2012;164(4):524-9.

52. van Reedt Dortland AK, Giltay EJ, van Veen T, Zitman FG, Penninx BW. Longitudinal relationship of depressive and anxiety symptoms with dyslipidemia and abdominal obesity. Psychosom Med. 2013;75(1):83-9.

53. Whooley MA, de Jonge $\mathbf{P}$, Vittinghoff $\mathbf{E}$, et al. Depressive symptoms, health behaviors, and risk of cardiovascular events in patients with coronary heart disease. JAMA. 2008;300(20):2379-88. https://doi.org/ 10.1001/jama.2008.711

54. Williams SL, French DP. What are the most effective intervention techniques for changing physical activity self-efficacy and physical activity behaviour-and are they the same?Health Educ Res. 2011;26(2):308-22. https://doi.org/10.1093/her/cyr005

55. Luszczynska A, Tryburcy M, Schwarzer R. Improving fruit and vegetable consumption: a self-efficacy intervention compared with a combined self-efficacy and planning intervention. Health Educ Res. 2007;22(5):630-8. https://doi.org/10.1093/her/cyl133

56. Edworthy SM, Devins GM. Improving medication adherence through patient education distinguishing between appropriate and inappropriate utilization. Patient Education Study Group. The Journal of rheumatology. 1999;26(8): 1793-801.

57. Wolever RQ, Dreusicke M, Fikkan J, Hawkins TV, Yeung S, Wakefield $\mathbf{J}$, et al. Integrative Health Coaching for Patients With Type 2 Diabetes. The Diabetes Educator. 2010;36(4):629-39. https://doi.org/10.1177/ 0145721710371523

58. Maxwell SE, Cole DA. Bias in cross-sectional analyses of longitudinal mediation. Psychol Methods. 2007;12(1):23.

59. Davidson KW, Burg MM, Kronish IM, Shimbo D, Dettenborn L, Mehran R, et al. Association of anhedonia with recurrent major adverse cardiac events and mortality 1 year after acute coronary syndrome. Arch Gen Psychiatry. 2010;67(5):480-8.

60. Streiner DL, Norman GR, Cairney J. Health measurement scales: a practical guide to their development and use: Oxford University Press, USA; 2014. 